\title{
The Quilt Company: An Experiential Case In The Behavioral Effects Of Accounting And Measurement Upon Manufacturing Quality
}

Katherine J. Silvester, Siena College, USA

\begin{abstract}
Accounting and business students routinely develop "profits myopia" when asked to analyze business situations. Although they have been taught and purportedly believe that they understand the vital importance of quality, students do not easily internalize quality concepts. The purpose of this case is to help students become aware of their own naivety and tendencies to ignore quality when attempting to maximize profits. The author has tested this case for over a decade in a variety of educational venues (including executive, graduate, and advanced undergraduate classes with substantial numbers of both domestic and international students). With rare exception, student teams repeatedly chose short-term profits over intermediate and long-term quality when placed under competitive pressure. This experiential case allows the professor to explore the behavioral effects of measurement upon quality and to raise the students' awareness of the complexities and interplay of measurement and quality.
\end{abstract}

Keywords: quality, job costing; manufacturing; experiential

\section{INTRODUCTION}

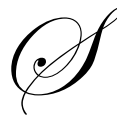

tudents believe that they understand the importance of product quality in the manufacturing and business environment. The topic of quality management is covered in texts within every field, and so students are constantly barraged by the total quality mantra. Unfortunately, a purely academic discussion of quality concepts can leave many students with a fairly superficial understanding of quality management, coupled with a naïve belief that they actually do understand the complexity of the issues involved.

Within the fields of Business and Management, total quality management is routinely incorporated into classroom lectures and cases in accounting, finance, operations management, statistics, etc. This case provides a rare opportunity for the college business professor to offer students an experiential opportunity to explore and deepen their own understanding of how measurement, quality, and competitive pressures interrelate.

Published over two decades ago, Tyson's [1986] classroom exercise provided a "fun" experiential method for teaching job costing to accounting students. While primarily oriented toward the mechanics of job costing, Tyson noted the possibility of using his case as the foundation for exploring "a number of provocative issues regarding standard costing and quality control" with the students. This article has taken up Tyson's challenge in the area of quality. Using the quilt pattern and some of the basic forms contained in Tyson's article, this article provides an original and substantive extension of Tyson's work. The competition, construct, and behavioral discussion described in the Quilt Company Experiential Case provide a unique opportunity for the professor to challenge, deepen, and hone his students' understanding of quality related issues. 


\section{TARGET AUDIENCE}

This case has been effectively and successfully used for undergraduate accounting majors in their senior year, first year MBAs, and Executive Education Courses. In general, students should have already been introduced to basic cost accounting and total quality management concepts. Manufacturing and Business Executives with extensive experience, provide a particularly rich environment for the simulation and its ensuing discussion.

\section{SIMULATION TIMING}

The simulation portion of the case requires one 80 minute class period. Students should feel rushed to complete their quilts, and a period of about 45 minutes for actual quilt construction seems to work well. This sense of urgency and pressure is actually very useful. It will reveal/encourage many dysfunctional behaviors among the student teams and provide extensive fodder for discussion. The remaining 35 minutes of the class period is sufficient for the initial production of the financial statements, as well as the Quality Control Review by the Customer. If time is an issue, the student teams can be instructed to work on their Accounting Paperwork at the same time as their quilts are being constructed. This will result in even more dysfunctional behaviors, due to the emphasis on the accounting and measurement process.

The discussion portion of the case also requires an additional 50-80 minute class period.

This case is particularly well suited to an extended night class, where the discussion period can immediately follow the simulation period.

\section{SIMULATION STRUCTURE AND ORGANIZATION}

Students should be formed into teams of 4 or 5 students, and each student should be given a copy of the Student Instruction Packet. Student teams are told that they are going to be placed in a competitive situation during the next class and to prepare for the simulation. In order to provide the "right" context for the competition, the instructor can read the Quilt Company Overview to the students, emphasizing the competitive nature of the upcoming competition.

In the absence of specified quality guidelines, the teams are required to organize production teams, analyze a customer-specified pattern, produce paper quilt(s), job order cost their production, and produce financial statements. Although the need for a quality product is strongly implied in the Company History, the teams are not specifically required to measure and report on the quality of their product. Because of the accounting orientation of the reporting guidelines, students automatically believe that this is an "accounting exercise". Therefore, with great hilarity and energy, they regularly produce large numbers of poorly constructed quilts in order to maximize paper profits.

Following the posting of their financial statements, students regularly brag about the volume of their production, the size of their paper profits, and laugh about the "pitiful" quality of their product. ${ }^{1}$ The teams are now perfectly positioned to face their own denouement. At this point, the teams "meet" their customer ${ }^{2}$ for the first time. The customer, John Hawthorne, performs a quality inspection and then returns all unsatisfactory products to the teams. It is useful for the customer to specifically point out the quality problems in each quilt (i.e., missing pieces, sloppy gluing, ripped rather than cut materials). Teams are specifically advised that that, obviously, returned quilts

\footnotetext{
${ }^{1}$ During the simulation, the professor can wander around the classroom, taking notes on student comments overheard during the simulation. I generally just write the comments on overhead transparencies. These comments can product a hilarious response, when reviewed by the students who have just completed the competition. Sample comments have included: "Just shut up and glue!" "I feel sorry for this customer." "Who cares if it's junk, just get it done." "Can we sell these at the Dollar Store?"

${ }^{2}$ The designation of the surprise customer is an important one. We have used operations or management professors who have previously taught students about quality, Quality Assurance managers from an organization's own ranks, and other individuals respected by the students.
} 
do not generate revenue. Accordingly, each team's reported Net Income plummets. With great energy, students will defend their low quality production and challenge the validity of the unexpected quality inspection.

\section{DISCUSSION PERIOD}

Following the unanticipated quality review of their quilt production, the instructor can challenge the students in a number of ways. For example, "why didn't you choose quality as a goal?" "Why did you make garbage?" "Do you only make a quality product when forced to do so?" "What were your goals when the competition began?" Exhibit 1 includes some suggested Discussion Questions that can be used to guide the discussion. Typical student comments and potential faculty responses are also included.

As the faculty member guides students in this simulation, it is crucial that the students feel playfully challenged, and not criticized. As they proceed through the guided analysis of their own behaviors, they will begin to appreciate the complexities inherent in measurement, quality, and management. In this way, students may begin to internalize that: (1) measurement affects performance, and (2) "quality is neither automatic nor simple".

\section{EXHIBIT 1}

\section{Discussion Questions}

1. Did your team have an explicit or implicit goal before production began?

a. Students:

1. High volume is the typical answer.

b. Faculty:

1. High quality is usually only chosen by a very small minority of teams.

2. Why did so many teams chose high production volume as their goal?

a. Students:

1. Assumption that highest Net Income was winner

2. Assumption that high production led to high Net Income

3. Lack of specific management directives regarding quality.

b. Faculty:

1. Teams ignored direction that company produced "hand-made, special order quilts for over 100 years." Teams ignored that this was a custom-designed, special order for a specific customer and the implications this had for quality.

2. There appears to be an automatic bias toward meeting production goals, at the sacrifice of quality.

3. Specific management direction and leadership regarding quality is needed. It is management's responsibility to communicate goals effectively. If management's communication is ineffective, employees will self-direct. When employees self-direct, they may optimize their own self-interest or they may optimize assumed company goals.

3. Do you only produce a quality product when told or forced to do so?

a. Students:

1. Presence of accounting measurement confounded students' goals.

2. Sense of urgency drove students to make compromises.

3. This isn't a real situation. Obviously, students or employees would act differently in a real life situation. 
b. Faculty:

1. Accounting and measurement are always present in a business situation. The Hawthorne effect is a useful discussion here. ${ }^{3}$ The key issue is that measurement and observation affect performance. Measurement is not a neutral event. People react to measurement, and their reactions may be functional or dysfunctional, congruent or non-congruent with organizational goals.

2. This isn't a real-life situation. We were not making medical devices, for example. However, you also were not under real financial or career pressure. ${ }^{4}$ Yet, the tendency to want to "meet the numbers" and many dysfunctional behaviors still appeared in your teams.

4. Why did teams spend so much time planning to minimize scrap? Note: It costs a 4 person team $\$ .80$ per minute in direct labor. An index card costs only $\$ .50$ per card.

a. Students:

1. I don't know.... It's wrong to waste....

2. Scrap is more visible than labor.

3. Scrap "stays around" physically; wasted labor does not "stay around"

b. Faculty:

1. There can be a tendency to fixate on what is visible, rather than on what is "invisible." Management must guard against automatically grabbing only the "low hanging apples."

5. Optional Accounting Questions: How did your team decide how much to spend on overhead supplies (rulers, glue sticks, scissors)? How did your decision affect your team's financial profits?

a. Students:

1. Students usually indicate that they tried to use the minimum amount of overhead supplies that they needed to reach their production goals.

2. Students will notice, with surprise, that their use of overhead did not affect their reported Net Income.

b. Faculty:

1. During interim accounting periods, the over and under-applied overhead account is typically not closed out to individual projects. Therefore, jobs are only charged at the budgeted overhead rate, not their actual usage of overhead. Therefore, overhead supplies are essentially a "free good".

2. This "free good" realization can lead to significant problems in future periods, resulting in overuse and waste of the common overhead supplies.

6. Optional Quality Questions: Were the quality problems that your team encountered the result of design quality failure and/or the result of conformance quality failure? Which category of the Cost of Quality (Prevention Costs, Appraisal Costs, Internal Failure Costs, or External Failure Costs) were highest for your team?

a. Students:

1. It was a bad design, and it was poorly made.

2. We should have had more Appraisal (inspection) Costs. That would have prevented our high External Failure Costs (all of the returns).

3. Our External Failure Costs are equal to our lost revenues from the returned quilts.

\footnotetext{
${ }^{3}$ The Hawthorne Effect was observed and discussed during a study of the changes in working conditions in the Hawthorne production plant of Western Electric in Chicago during the 1920s and 1930s. Following a study of the plant production processes and employees, a number of changes were introduced by management. Production improved following the changes. It became clear during the study, however, that production increased not because of actual changes in the working conditions initiated by the plant's management, but because management demonstrated interest in the workers and the improvements. In other words, attention and measurement affected performance.

${ }^{4}$ Any number of readings are available to show how production pressure affects performance. One classic reading is the Pfizer Heart Valve Failures article (Carley, 1991). Current events provide numerous other examples, which students will cite, if encouraged to do so. The point is that the conflict between production volume pressure and quality is a classic problem - a problem that is always lurking, but that is manageable.
} 
b. Faculty:

1. The design was specified by the customer, and therefore met the customer's requirements (by definition). Therefore, there is not a design conformance issue.

2. The problem was in the team's lack of conformance to the customer's design specifications. This is a quality conformance issue.

3. Appraisal (inspection) costs are certainly a helpful immediate approach to reducing both Internal and External Failure Costs. However, Prevention is a more effective long-term systemic solution.

4. External Failure Costs are frequently hidden. In a real world situation, the Quilt Company could have experienced a significant loss of reputation. Although not directly measurable, the opportunity cost of future lost sales can be extremely significant.

7. Concluding Comments

a. Faculty:

1. Short-term goals can overwhelm long-term goals.

2. Production pressures emphasize a short-term orientation.

3. Profit goals can override quality goals.

4. Periodic accounting reporting process naturally emphasizes short-term profit myopia.

5. Prevention of short-term profit myopia requires deliberate and effective management action.

6. It is management's responsibility to enact functional and effective measurement systems.

7. Effective measurement systems reflect and support corporate goals.

8. Effective measures must be objective, observable, quantifiable, and timely.

9. Effective measurement systems include regular reporting, feedback loops, and appropriate incentives.

\section{ATTACHMENT A}

\section{STUDENT INSTRUCTION PACKET}

\section{Quilt Company, Inc. Job Order Costing Simulation}

\section{Section A: Overview}

Quilt Company, Inc. has been producing hand-made, special order quilts for over 100 years. It has a large number of separate manufacturing plants located in small rural American towns and villages. Unfortunately, over the years, the demand for such costly, hand-made quilts has been decreasing. Therefore, the executive management of Quilt Company, Inc. has decided to permanently close four of its plants. In order to decide which plants should be closed, each plant has sent a team of its best employees to today's competition. Each team will be given the opportunity to produce one or more quilts. At the end of the competition, each team will deliver its quilts and report its corresponding revenues, costs, and profits. Subsequently, four teams will be selected for closing.

\section{Section B: Team Instructions}

1. Pre-Competition Planning. Each team will be given a copy of this Student Instruction Packet, which includes Accounting Forms, to review before the day of the competition. Be sure to review the basics of Job Cost Accounting from your text, so that you can properly prepare your Financial Reports. Please note that the teams will not be given the quilt pattern until the last possible moment. This will allow us to test for the team's flexibility, creativity, and agility in responding to crisis.

2. When Competition Begins. Your team will be given a Team Number. Fill in the Start Time on the Time Ticket, Form 201, for your Team. The Start Time will be the same for every team, and it will be announced by the Moderator at the beginning of the exercise, along with the maximum amount of time allowed for quilt manufacturing. 
3. The teams will receive the Quilt Pattern. Using the pattern provided, decide how to construct and deliver at least one quilt in the time allowed. Decide how many quilts you will attempt to manufacture.

4. Requisition the appropriate amount of materials and supplies from the Stores Clerk. Teams must submit a properly completed Requisition Form to the Stores Clerk in order to obtain materials and supplies. The list of items that you can requisition is contained below in Section C, along with the cost of both requisitioned and non-requisitioned items for which you will be charged.

Create a numbering system to keep track of your requisitions (e.g., requisition number one for team 5 might be Req. 5-1). Material Requisitions must be filled out correctly and completely or the Stores Clerk will not accept and fulfill them. Once the Stores Clerk approves your Requisitions, he will return the Signed Requisition Form to you, along with the requisitioned items.

Each team is guaranteed access to one ruler, one glue stick, and one pair of scissors. Additional manufacturing materials and supplies will be distributed upon requisition on a first-come, first-serve basis until all supplies are exhausted. (Anti-competitive behaviors will not be allowed. For example, teams will not be allowed to purchase all supplies in order to drive the competing teams out of the market.) The Stores Clerk will not issue refunds or accept returns. However, teams may trade freely among themselves on a secondary market. Additionally, teams must use the materials and supplies provided during the manufacturing phase. No "self-provided" materials or supplies will be allowed.

5. Construct at least one quilt following the specifications on your assigned quilt pattern. Glue each quilt to a sheet of White Background Paper. Cut off the excess White Background Paper. Write your team number on the back of the completed quilt. Deliver the quilt to the "Delivery Truck" by taping the quilt to the front wall of the room.

6. When your last quilt is delivered, the Moderator will validate the end time on your Time Ticket. If the end time is not validated by the Moderator, it will be assumed that your team used the maximum time allowed.

7. There are no Ending Work-in-Process inventories allowed. In other words, any quilts that are still "in process" at the end of the competition must be included in the Team's cost, but the incomplete quilts will not generate any revenue.

8. Complete the Time Ticket, the Job Cost Sheet, and the Team Financial Statement.

9. Post your Team Financial Statement on the front wall of the room.

10. Clean up your work area and return all supplies.

11. Review all the Delivered Quilts and the Financial Statements posted to the front wall of the room. Is there a relationship between the number of quilts delivered and a team's Financial Statement? 
Section C: Materials, Supplies, and Costs

\section{$\underline{\text { Revenue }}$}

Direct Cost

Index Card, 3" x 5", all colors

White Background Paper, 8-1/2" x 11"

Labor

General \& Administrative Cost

Moderator Salary

Budgeted Applied Overhead Rate

Actual Overhead Cost

Non-Requisitioned Costs

Stores Clerk Salary

Rent

Utilities

Misc. variable overhead

Requisitioned Costs

Scissors

Glue Stick

Rulers
$\$ 50.00$ per quilt

50 cents per card

$\$ 1.00$ per sheet

20 cents per person per minute

$\$ 5$ per team for entire competition

30 cents per person per minute

$\$ 10$ per team for entire competition $\$ 10$ per team for entire competition $\$ 2$ per team for entire competition $\$ 3$ per quilt delivered

$\$ 10$ per pair

$\$ 5$ per stick

$\$ 5$ per ruler

Section D: Forms and Reporting

Form \# 201

\section{TEAM TIME CARD}

Team Number

Date:

Job \#

Job Name:

Time Production Began: Time Production Ended:

\begin{tabular}{|l|l|l|l|}
\hline Employee Name & Minutes Worked & Pay Rate Per Minute & Total \\
\hline & & & \\
\hline & & & \\
\hline & & & \\
\hline & & & \\
\hline & & & \\
\hline
\end{tabular}

Approved By:

Job Team Leader

Payroll Clerk 


\section{Form \# 202}

\section{REQUISITION FORM FOR DIRECT MATERIALS}

Date:

Team Number

Job Number

Customer Name:

\begin{tabular}{|l|l|l|l|l|}
\hline Item & Description (size \& color) & Quantity & Cost Per Item & Total Cost \\
\hline & & & & \\
\hline & & & & \\
\hline & & & Total For \\
Requisition & $\$$ \\
\hline
\end{tabular}

Approved By:

Processed By:

Job Team Leader

Inventory Clerk

Form \# 203

\section{REQUISITION FORM FOR OVERHEAD SUPPLIES}

Date:

Job Number

Team Number

Customer Name:

\begin{tabular}{|l|l|l|l|l|}
\hline Item & Description (size \& color) & Quantity & Cost Per Item & Total Cost \\
\hline & & & & \\
\hline & & & & \\
\hline & & & Total For \\
Requisition & $\$$ \\
\hline
\end{tabular}

Approved By:

Processed By:

Job Team Leader

Inventory Clerk 


\section{Form \# 204}

Team Number

\section{JOB COST SHEET}

Date

Job \#

Job Name:

\begin{tabular}{|l|l|l|l|}
\hline Input Source Document & \multicolumn{1}{|c|}{$\begin{array}{c}\text { Direct Labor } \\
\text { Cost }\end{array}$} & $\begin{array}{c}\text { Direct Materials } \\
\text { Cost }\end{array}$ & $\begin{array}{c}\text { Applied Overhead } \\
\text { Cost }\end{array}$ \\
\hline $\begin{array}{l}\text { Group Timecard } \\
\text { Dated: }\end{array}$ & & & \\
\hline Requisition \# & & & \\
\hline Requisition \# & & & \\
\hline & & & \\
\hline & & & \\
\hline & & & \\
\hline Totals & & & \\
\hline
\end{tabular}

Total Job Cost 
Form \# 205

Team Financial Statement Quilt Company Competition Income Statement

Team Number

Revenue: Quilts@\$50 each

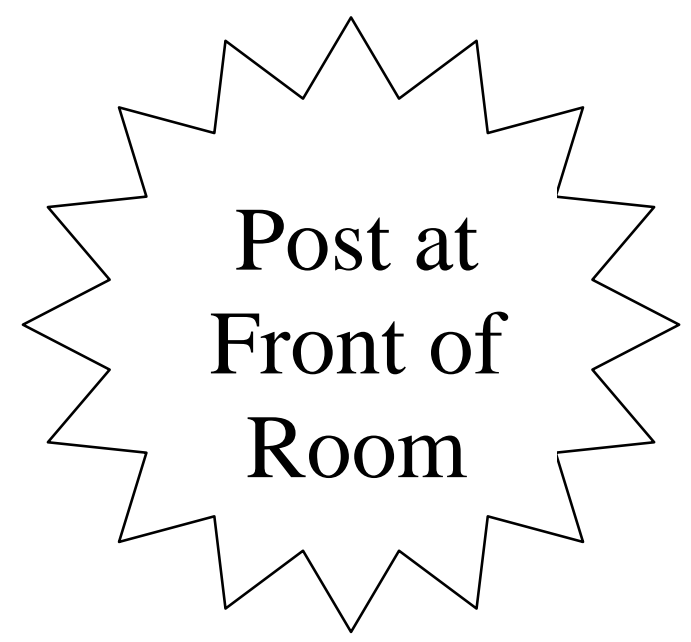

$\$$

Cost of Goods Sold:

Direct Labor

$\$$

Direct Materials

$\$$

Overhead

$\$$

Total Cost of Goods Sold:

$\$$

Gross Margin

$\$$

General, Administrative, \& Selling Expense

$\$$

Net Income

$\$$

Balance Sheet

Selected Other Assets:

Manufacturing Overhead Control: Actual Overhead Cost

$\$$

Applied Overhead

$\$$

Account Balance

$\$$

Is Overhead Under or Over-Applied? 
ATTACHMENT B

Quilt Pattern: Special Order Job \# 888 for John Hawthorne

$$
6 "
$$

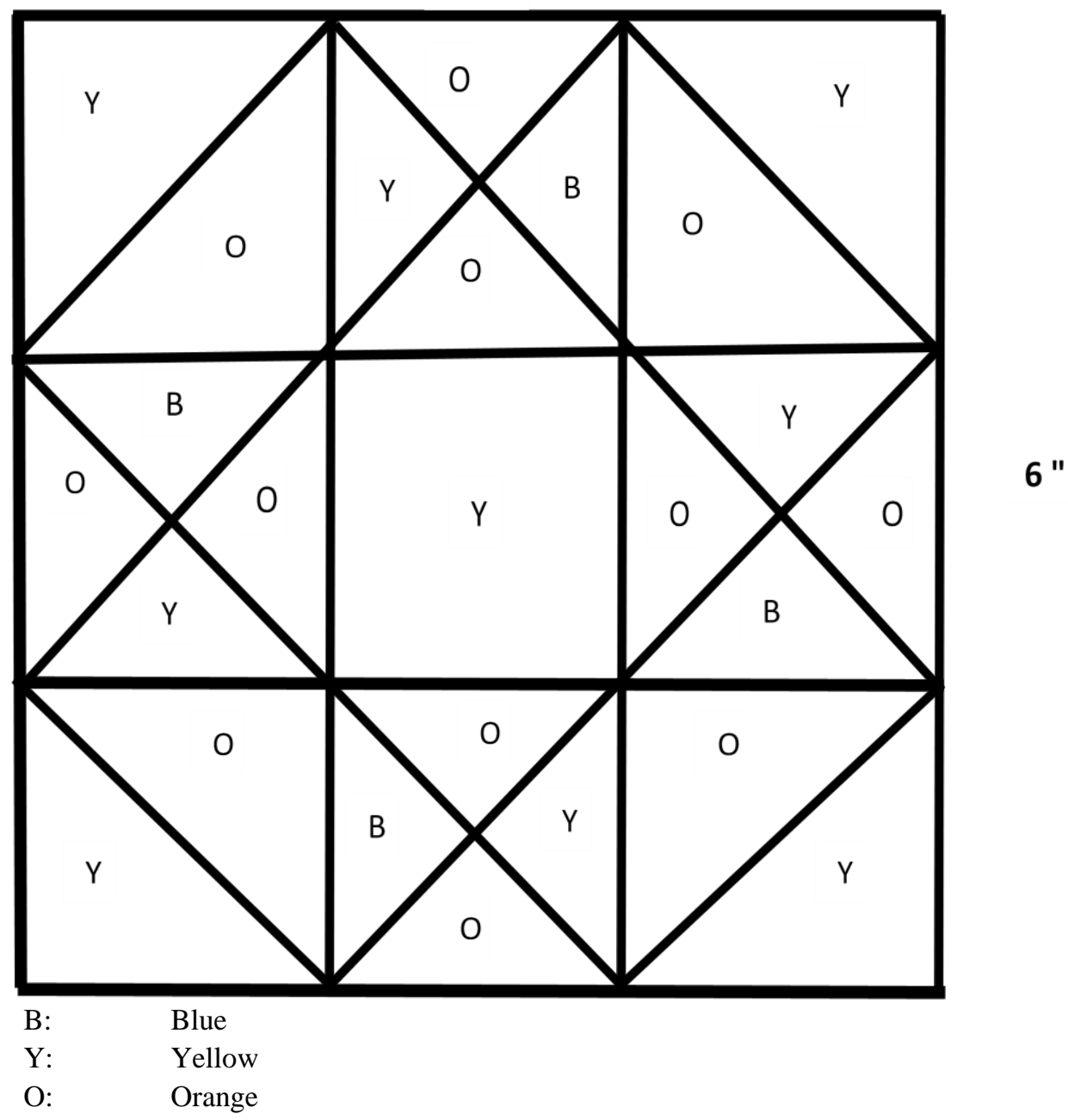




\section{AUTHOR INFORMATION}

Katherine Silvester earned her Ph.D. in Accounting from the University of Maryland. Her primary area of interest centers upon managerial and cost accounting. With over a decade of professional experience in accounting and business management in the private sector, Dr. Silvester has worked for Martin Marietta, Alcoa, and various Department of Defense software consultants. Dr. Silvester has published in journals such as The Journal of Cost Managment, the Journal of Product Innovation Management, and the Journal of Accounting and Public Policy. Her teaching philosophy focuses upon strengthening student/professor interactions within an affective learning environment.

\section{REFERENCES}

1. Tyson, Thomas N. (Fall 1986). "Energize Your Accounting Class with a Simulation That's Fun for Students," Journal of Accounting Education, 117-123.

2. Horngren, Datar, Foster, Rajan, and Ittner (2008). Cost Accounting: A Managerial Emphasis, 13th Edition, Ch. 19, 664-697.

3. Carley, William M. "Fatal Flaws: Artificial Heart Valves That Fair Are Linked To Falsified Records," Wall Street Journal, November 7, 1991, pp. A1, A6.

\section{NOTES}

